\title{
Orbital Analysis of Natural Bonds, Calculations of the Functional Theory of Density Time-Dependent and Absorption Spectral of a Series of Rhodanine Derivatives
}

\author{
Koffi Alexis Respect Kouassi ${ }^{1}$, Anoubilé Benié ${ }^{1,2}$, N'Guessan kouakou Nobel ${ }^{1}$, Mamadou Guy-Richard \\ Koné $^{1, *}$, Adenidji Ganiyou ${ }^{4}$, Kouadio Valery Bohoussou ${ }^{1}$ and Wacothon Karime Coulibaly ${ }^{3}$ \\ ${ }^{1}$ Laboratoire de Thermodynamique et de Physico-Chimie du Milieu, UFR SFA, Université Nangui Abrogoua, \\ 02 BP 801 Abidjan 02, Côte d'Ivoire \\ ${ }^{2}$ Laboratoire de Chimie BioOrganique et de Substances Naturelles, UFR-SFA, Université Nangui Abrogoua, 02 \\ B.P. 801 Abidjan 02 Côte-d'Ivoire \\ ${ }^{3}$ UFR des Sciences Biologiques, Université Péléforo Gon Coulibaly, Korhogo, BP 1328, Cote d'Ivoire \\ ${ }^{4}$ Laboratoire de Constitution et réaction de la matière, UFR-SSMT, Université Félix Houphouët-Boigny 22 BP \\ 582 Abidjan 22, Côte d'Ivoire
}

\begin{abstract}
In this work, the density functional theory (DFT) method at the B3LYP/6-31 + G (d, p) level has used to determine the optimization of five rhodanine derivatives. The stability of the derivatives (7a-7e) of 5-arylidene rhodanine, the hyperconjugative interactions, the delocalization of the atomic charges was analyzed with the analysis of the Natural Bond Orbital (NBO). The electronic structures were discussed and the relocation of electronic density was determined. Molecular Electrostatic Potential (MEP), local density functional descriptors, border molecular orbitals and absorption spectrum were studied. Through the local Fukui reactivity indices, the carbon of the carbonyl group $(\mathrm{C}=\mathrm{O})$ is the preferential site of nucleophilic attack and the sulfur atom linked to the trigonal carbon $(\mathrm{C}=\mathrm{S})$ is the preferential site of electrophile attack. Analysis of the global descriptors revealed that compound $7 \mathrm{c}$ is the most reactive with an energy difference between the frontier orbitals of $\Delta$ Egap $=3.305 \mathrm{eV}$. Furthermore, this compound $7 \mathrm{c}$ is the less stable, the softest and has the greatest electronic exchange capacity of all studied compounds. The intramolecular electronic transitions which stabilize these compounds are $\mathrm{LP} \rightarrow \pi *$ for $7 \mathrm{a}$ and $7 \mathrm{~d}$ and $\sigma \rightarrow \sigma *$ for $7 \mathrm{~b}, 7 \mathrm{c}$ and $7 \mathrm{e}$. The rhodanine derivatives are more reactive and more soluble in polar solvents.
\end{abstract}

Keywords: TD-DFT; NBO; Chemical reactivity; Local descriptors.

\section{Introduction}

Rhodanine also called 2-thioxo thiazolidin-4-one, belongs to the family of thiazolinones which is a very important class of heterocyclic compounds having very diverse and interesting pharmacological and biochemical activities ${ }^{1}$. These activities justify the investigation of rhodanine derivatives for the development of new therapeutic agents ${ }^{2}$. The skeleton of rhodanine is present in a very wide range of compounds which have very different biological properties. It gives the compounds a privileged structure. Indeed, the skeleton is biocompatible and acts as a non-mutagenic agent ${ }^{3}$, which provides it with the profile of "drug-like". The 5-arylidene rhodanine represents the most studied derivatives currently.
Today, many derivatives have been synthesized, characterized and tested for their anti-microbial, antiviral and anti-convulsingproperties ${ }^{4-6}$. Even if modern analysis methods give access to a level of rationalization of results, they remain disabled as soon as one wishes to anticipate the performance of the system. Quantum theories of chemical reactivity currently make it possible to justify and/or predict rationally experimental regioselectivity. Predicting the reactivity and selectivity of a chemical process is crucial. It is mainly based on two qualitative models which are the theory of frontier orbitals and the conceptual DFT. Reactivity descriptors derived from functional density theory (DFT) have recently been the focus of researchers in organic chemistry as a tool 
to explain the global and/or local reactivity of molecules ${ }^{7}$. Descriptors are defined in terms of general chemical parameters such as Ionization Potential (IP), Electronic Affinity (EA), electronegativity $(\mu)$, hardness $(\eta)$, chemical potential $(\mu)$, electrophilic index $(\omega)$ and local reactivity descriptors such as Fukui function and local softness ${ }^{8}$. This is the framework for our work, which aims to study the properties of a series of rhodanine derivatives (Table 1) synthesized from 5-arylidene rhodanine by Coulibaly et al. ${ }^{9}$ and predict their applications. We provide a full description of the chemical reactivity of five rhodanine derivatives from the analysis of the Natural Bond Orbital (NBO) as well as electronic properties like HOMO-LUMO energy gap, chemical hardness and chemical potential. In addition, the Molecular Electrostatic Potential (MEP) and UV-visible analysis were studied using theoretical calculations to provide information on the charge transfer within each molecule. Calculations carried out in this wok are obtained by the method (TD) DFT/B3LYP with a set of bases $6-31+G(d, p)$.

Table 1. 2D code and structure of derivatives of Bis (5-arylidene rhodanine) with 1,2-ethylene diamine.

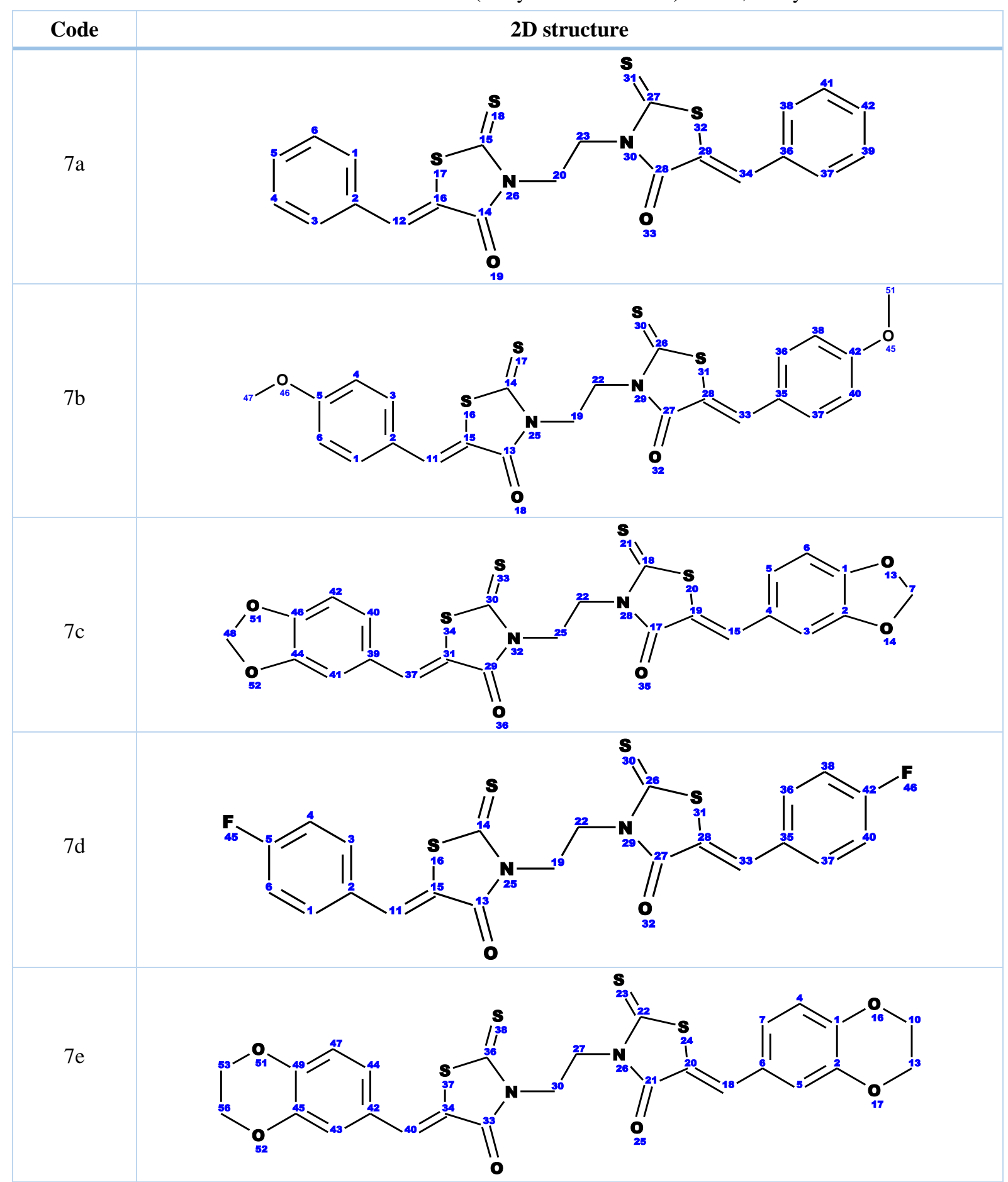




\section{Material and Methods}

\subsection{Calculation Theory Level}

The geometry optimization and various quantum chemistry parameters were calculated with the aid of Density Functional Theory (DFT) at the theoretical B3LYP/6-31 + G (d, p) level ${ }^{10-12}$, is shown to be very effective for the study of polyelectronic systems ${ }^{13,14}$. It presents much fewer convergence problems than those commonly encountered for pure DFT methods. Thus the B3LYP method was used in this document to perform quantum calculations. Then, complete geometric optimizations of all the compounds were performed at level B3LYP / 6-31 + G (d, p) using the Gaussian 09 program and the Gauss View 5.0 molecular visualization program ${ }^{15}$. For understanding electronic properties, electronic transitions in the UV spectral region were calculated by the TD-DFT method with a B3LYP level and a set of bases 6-31+ $\mathrm{G}(\mathrm{d}, \mathrm{p})$. HOMO and LUMO energies were calculated using the DFT method from the geometry of the ground state of the molecules taken in the gas phase as well as in different solvents. NBO (Natural Bond Orbital), Fukui function and Molecular Electrostatic Potential (MEP) analyzes of the compounds were evaluated.

\subsection{Thermodynamic parameters of the formation}

The calculation of enthalpy and free enthalpy was carried out using formulas proposed by Otchersky et al. ${ }^{16}$ :

$$
\Delta H_{f}^{0}(M, 0 K)=\sum_{a t o m s} x \Delta H_{f}^{0}(X, 0 K)-\sum D_{0}
$$

$\Delta H_{f}^{0}(M, 298 K)=\Delta H_{f}^{0}(M, 0 K)+\left(H_{M}^{0}(298 K)-H_{M}^{0}(0 K)\right)-\sum_{a t o m s} x\left(H_{X}^{0}(298 K)-H_{X}^{0}(0 K)\right)$

where $\sum D_{0}=\sum x \varepsilon_{0}-\varepsilon_{0}(M)+\varepsilon_{Z P E}$

$\sum D_{0}$ : Atomizing energy

$\varepsilon_{0}(M)$ : Total energy of the molecule

$\varepsilon_{Z P E}:$ Zero-point energy of the molecule

$H_{X}^{0}(298 K)-H_{X}^{0}(0 K)$ : Enthalpy corrections for atomic elements. These values are included in the Janaf table ${ }^{17}$.

$$
\Delta G_{f}^{0}(M, 298 K)=\Delta H_{f}^{0}(M, 298 K)-T \Delta S_{f}^{0}(M, 298 K)
$$

$H_{M}^{0}(298 K)-H_{M}^{0}(0 K)=H_{c o r r}-\varepsilon_{Z P E}(M):$

Molecule enthalpy correction

$H_{\text {corr }}$ : Thermal correction enthalpy.

$\Delta S_{f}^{0}(M, 298 K)=S_{M}-\sum_{a t o m s} x \Delta S(298 K)$

$x$ : Number of atoms of $\mathrm{X}$ in the Molecule

\subsection{Global Descriptors}

Within the framework of the validity of Koopmans' theorem ${ }^{18}$, the energies of frontier orbitals are given by :

$$
P I=-E_{\text {номо }}, A E=-E_{\text {LUMо }}
$$

This theorem relates the energies of HOMO and LUMO with the ionization potential (PI) and electronic affinity (AE), respectively. Although there is no formal proof of this theorem within the DFT, its validity is generally accepted. The expressions of $\eta$ and $\mu$ are given by the following relations ${ }^{13}$ :

$\mu=-\frac{P I+A E}{2}, \eta=\frac{P I-A E}{2}$

Other descriptors such as chemical potential $(\mu)$, ionization potential (PI), electronic affinity (AE), electron exchange energy $\left(\Delta \mathrm{E}_{\mathrm{T}}\right)$ and chemical hardness $(\eta)$ which allow rationalizing the chemical behavior of molecules are obtained from the following expressions:

$\omega=\frac{\mu^{2}}{2 \eta}, \quad \Delta \mathrm{E}_{T}=-\frac{\eta}{4}$

The frontier orbital HOMO (Highest Occupied Molecular Orbital) and LUMO (Lowest Unoccupied Molecular Orbital) of a chemical species are very important to define its reactivity ${ }^{19}$. One of the pioneers to highlight the role of orbitals in the mechanisms of chemical reactivity is Fukui ${ }^{20}$.
The energy of the lowest unoccupied molecular orbital provides information on the ability of the molecule to accept electrons.

The lower the value of LUMO, the more electrons the molecule accepts. In addition to the energy of HOMO and LUMO, the energy gap can be exploited to effectively predict the evolution of the reactivity and chemical stability of a series of molecules. A higher value of the difference energy $\Delta \mathrm{E}=\mathrm{E}_{\mathrm{LUMO}}-\mathrm{E}_{\mathrm{HOMO}}$ of a molecule in a series reflect its lower chemical reactivity compared to the other compounds of the series. However, a lower value of the energy gap $(\Delta \mathrm{E})$ indicates a greater reactivity of the molecule and conversely a low chemical stability ${ }^{21,22}$.

\subsection{Local Descriptors}

The Fukui function ${ }^{23,24,11}$ of a molecule provides information on reactive sites and the method of understanding as well as the categorization of chemical reactions. The atom with the highest Fukui function value is a highly reactive site with respect to the other atoms in the molecule. The use of Fukui functions for site selectivity in compounds for been demonstrated using the DFT method at the theoretical level B3LYP / 6-31 + G (d, p). The Fukui function for a nucleophilic attack $\left(\boldsymbol{f}_{\boldsymbol{k}}^{+}\right)$, Fukui function for an electrophilic attack $\left(\boldsymbol{f}_{\boldsymbol{k}}^{-}\right)$and Fukui function for nucleophilic, electrophilic and free radical attacks has 
a radical attack $\left(\boldsymbol{f}_{\boldsymbol{k}}^{\mathbf{0}}\right)$ are given by the following relationships:

$f_{k}^{+}=q_{k}(N+1)-q_{k}(N)$ for a nucleophilic attack;

$\boldsymbol{f}_{\boldsymbol{k}}^{-}=\boldsymbol{q}_{k}(\boldsymbol{N})-\boldsymbol{q}_{k}(\boldsymbol{N}-1)$ for an electrophilic attack;

$f_{k}^{0}=\frac{1}{2}\left[q_{k}(N+1)-q_{k}(N-1)\right]$ for a radical attack.

Where $\boldsymbol{q}_{\boldsymbol{k}}$ is the atomic charge of the $\mathrm{k}^{\text {th }}$ atom site in the neutral $(\mathrm{N})$, anionic $(\mathrm{N}+1)$, cationic $(\mathrm{N}-1)$ chemical species, respectively. The atom with the highest Fukui function value is the most reactive during the reaction. The three Fukui functions multiplied by global softness $\mathrm{S}$ provide three different local softness indices for any particular atom (k) ${ }^{25}$. These can be written as follows:

$\boldsymbol{S}_{\boldsymbol{k}}^{+}=\mathbf{S} \boldsymbol{f}_{\boldsymbol{k}}^{+}$suitable for nucleophilic attack studies;

$\boldsymbol{S}_{\boldsymbol{k}}^{-}=\mathbf{S} \boldsymbol{f}_{\boldsymbol{k}}^{-}$suitable for electrophilic attack studies;

$\boldsymbol{S}_{\boldsymbol{k}}^{\mathbf{0}+}=\mathbf{S} \boldsymbol{f}_{\boldsymbol{k}}^{\mathbf{0}}$ suitable for radical attack studies.

\subsection{Natural Bond Orbital (NBO) analysis}

NBO analysis shows the interaction between donor type NBO (filled or binding NBO) and acceptor type
NBO (empty NBO or anti-binder). It provides an effective method for studying intra and intermolecular interactions ${ }^{26}$. NBO analysis is performed by examining all possible interactions between filled Lewis NBO and empty Lewis NBO and estimating their energy by second-order perturbation theory ${ }^{27}$. The stabilization energy $\mathrm{E}_{2}{ }^{27}$ associated with the delocalization of electrons between the donor NBO (i) of electrons and the acceptor NBO (j) of electrons is evaluated according to the equation below.

$E_{2}=\Delta E(i j)=q_{i} \frac{(F(i j))^{2}}{\varepsilon_{j}-\varepsilon_{l}}=q_{i} \frac{F_{i j}{ }^{2}}{\Delta \varepsilon}$

$\mathrm{F}_{\mathrm{ij}}$ is an element of the Fock matrix, $\boldsymbol{q}_{\boldsymbol{i}}$ represents the occupation of the donor orbital, $\varepsilon_{\mathrm{i}}$ et $\varepsilon_{\mathrm{j}}$ are the energies of NBO orbitals of the acceptor and the donor respectively.

\section{Results and Discussion}

\subsection{Analysis of Thermodynamic Quantities of Compound Formation 7a-7e}

The results of the enthalpy and free enthalpy calculation are shown in Table 2.

Table 2. Thermodynamic quantities of formation of molecules 7a-7e at level B3LYP / 6-31 + G (d, p).

\begin{tabular}{|c|c|c|}
\hline Composés & $\boldsymbol{\Delta} \boldsymbol{H}(\mathbf{k c a l} / \mathbf{m o l})$ & $\boldsymbol{\Delta} \boldsymbol{G}(\mathbf{k c a l} / \mathbf{m o l})$ \\
\hline $\mathbf{7 a}$ & -1691.43 & -1278.50 \\
\hline $\mathbf{7 b}$ & -2047.06 & -1563.33 \\
\hline $\mathbf{7 c}$ & -2251.10 & -1776.02 \\
\hline $\mathbf{7 d}$ & -1781.14 & -1415.23 \\
\hline $\mathbf{7 e}$ & -2381.12 & -1850.84 \\
\hline
\end{tabular}

The variation of the enthalpy and the free reaction enthalpy informs respectively on the thermicity and the spontaneous chemical reaction. A negative enthalpy indicates an exothermic reaction, while a positive indicates an endothermic reaction. For the free reaction enthalpy, a negative value indicates a spontaneous reaction while a positive value suggests non-spontaneous formation reactions. All the values of the standard thermodynamic quantities of molecule formation are negative. Thus, the formation of all the compounds takes place spontaneously with the release of heat. At this level, it is noted that the quantities determined at the level of theory B3LYP/6-31 + G (d, p) confirm formation and existence of the series of rhodanine derivatives explored at the temperature $298.15 \mathrm{~K}$ and $\mathrm{P}=1 \mathrm{~atm}$.

\subsection{Frontier molecular orbitals analysis}

The study of global chemical reactivity of molecules is based on the calculation of global indices deduced from the electronic properties. The global descriptors of chemical reactivity of the rhodanine derivatives studied are given in Table 3.

Table 3. Some global descriptors and the dipole moment $\mu$ (Debye) of the compounds studied at level B3LYP/6$31+\mathrm{G}(\mathrm{d}, \mathrm{p})$.

\begin{tabular}{|c|c|c|c|c|c|c|}
\hline Molécules & $\mathbf{E}_{\text {Hомо }}(\mathbf{e V})$ & $\mathbf{E}_{\mathbf{L u m o}}(\mathbf{e V})$ & $\boldsymbol{\Delta E}(\mathbf{e V})$ & $\boldsymbol{\eta}(\mathbf{e V})$ & $\boldsymbol{\Delta E}_{\mathbf{T}}(\mathbf{e V})$ & $\boldsymbol{\mu}(\mathbf{D e b y e})$ \\
\hline $7 \mathrm{a}$ & -6.410 & -2.888 & 3.522 & 1.761 & -0.880 & 0.949 \\
\hline $7 \mathrm{~b}$ & -6.035 & -2.650 & 3.385 & 1.693 & -0.846 & 2.125 \\
\hline $7 \mathrm{c}$ & -6.085 & -2.780 & $\mathbf{3 . 3 0 5}$ & $\mathbf{1 . 6 5 3}$ & $\mathbf{- 0 . 8 2 6}$ & 6.115 \\
\hline $7 \mathrm{~d}$ & -6.496 & -2.982 & 3.514 & 1.757 & -0.878 & 0.591 \\
\hline $7 \mathrm{c}$ & -6.022 & -2.657 & 3.365 & 1.683 & -0.841 & 8.442 \\
\hline
\end{tabular}


The analysis in Table 3 shows that the compound 7c, which has the lowest energy difference values in the series $(\Delta \mathrm{E}=3.305 \mathrm{eV})$ is the most reactive and less stable molecule. Thus, the following sequence can be established in order of decreasing reactivity: $\Delta E: 7 c>7 e>7 b>7 d>7 a$. This decreasing order of stability is illustrated in Figure 1.

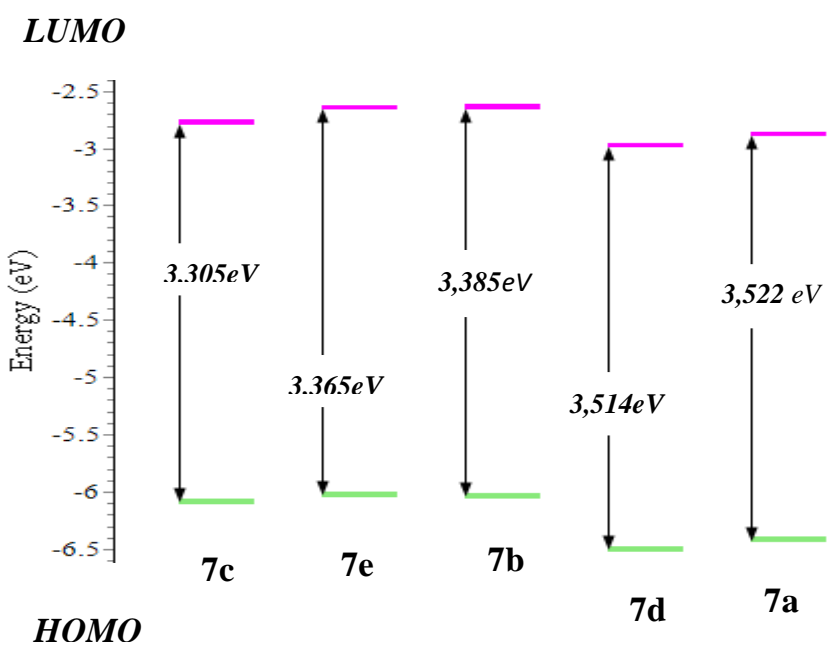

Figure 1. Energy distribution of HOMO and LUMO levels of compounds 7a-7e

The other descriptor analyzed is the chemical hardness ( $\boldsymbol{\eta})$, always the compound $\mathbf{7 c}$ having the lowest value (1.653eV) to that of the other compounds indicates that it is the softest among the compounds studied. Furthermore, this compound $\mathbf{7 c}$ has the greatest electronic exchange capacity with the highest value of the total exchange energy $\Delta \mathbf{E}_{\mathbf{T}}(\mathbf{- 0 , 8 2 6} \mathbf{e V})$. In summary, the global descriptors revealed that compound 7c is the most reactive, the less stable, the softest and it has the greatest electronic exchange capacity of all the compounds studied.

\subsection{Local Reactivity}

Local reactivity was studied by analyzing the molecular electrostatic potential (MEP) and the functions of Fukui.

\subsubsection{Molecular Electrostatic Potentials (MEP)}

Molecular electrostatic potential (MEP) simultaneously displays molecular shape, size and electrostatic potential in terms of color gradation. The map and outline of the molecules have been handy in analyzing the correlation between molecular structures and their physicochemical properties, including biomolecules and drugs ${ }^{28-31}$. It usually provides information about the chemical reactivity of a molecule. The electrostatic potential generated in the space around a molecule by the charge distribution is useful for understanding the electrophilic or nucleophilic properties ${ }^{32}$.
The 3D graphical representation of MEP of each compound (7a-7e) is illustrated in Figure 2. They were viewed with the Gauss View 5.0 program ${ }^{33}$. The different values of the electrostatic potential at the surface are represented by different colors (Figure 2). The different values of the electrostatic potential on the surface of these molecules are represented by different colors. The red color represents most negative electrostatic potential (electrophilic region), and the positive region which preferred site for nucleophilic attack symptoms as blue color and green represents regions close to zero potential or neutral site. The potential increases in order red $<$ orange $<$ yellow < green < cyan $<$ blue $<$ pink $<$ white ${ }^{34,35}$. In addition, chemical reactivity of molecules can be predicted using MEP details ${ }^{34}$. In MEP drawing, the negative potential regions are protonation or nucleophilic attack sites, while the positive potential regions are subjected to electrophilic attack. In this work, the MEP map clearly shows the different regions of the electrostatic potential in the molecules (Figure 2). As shown in Figure 2, apart from compound 7a which presents the benzene nuclei as electronegative zones, the negative regions (red color) are associated with the trigonal carbon atoms linked to the oxygen atoms $(\mathrm{C}=\mathrm{O})$ and the positive regions maximum (cyan to white color) are located on the hydrogen and sulfur atoms. These results provide information on the region where these compounds could intramolecularly interact. 


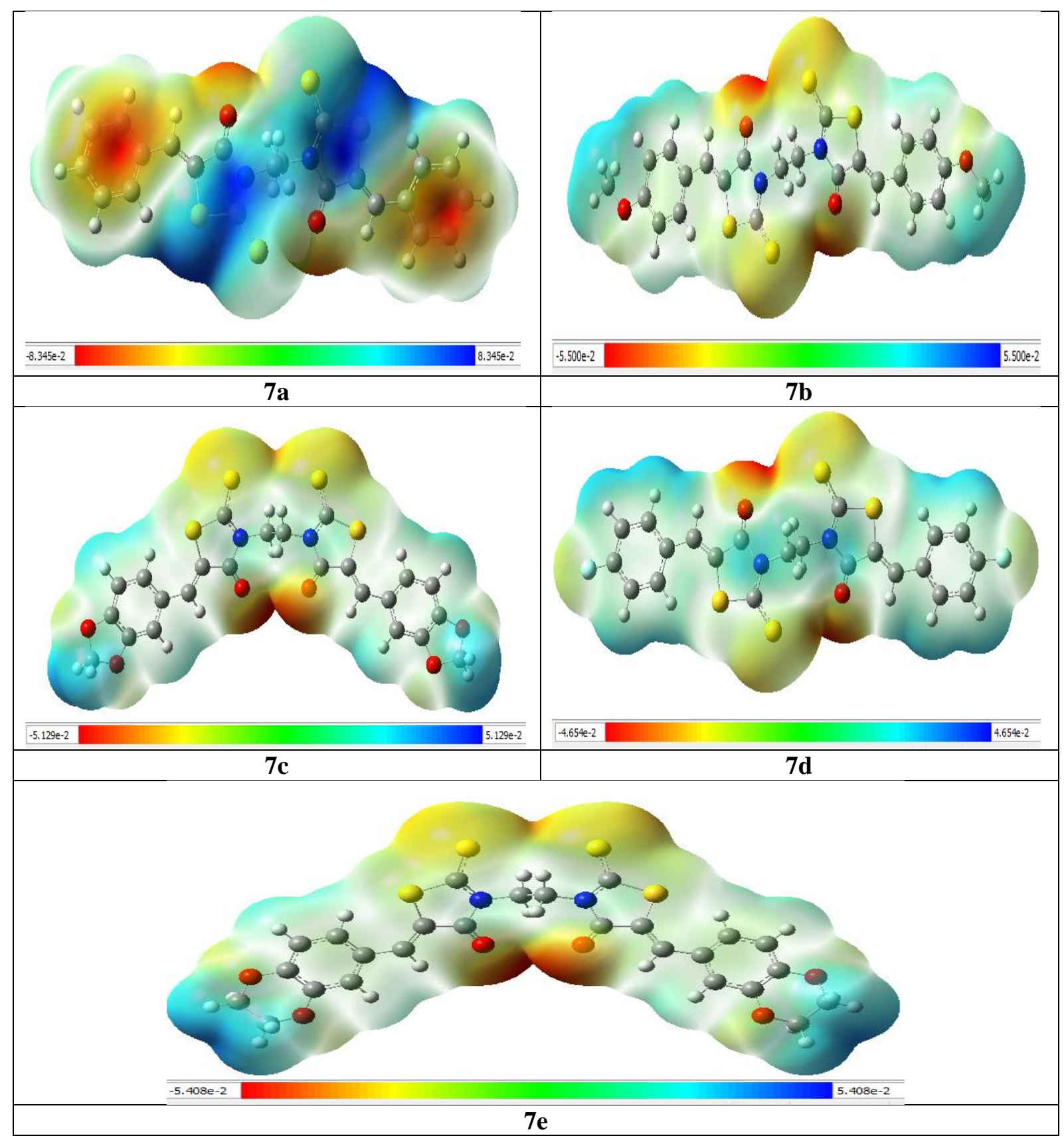

Figure 2: Distribution of Molecular electrostatic potentials of rhodanine derivatives 7a-7e

\subsubsection{Fukui indices}

In the present study, the electronic population was calculated by natural population analysis (NPA) by applying the DFT method at the B3LYP / 6-31G level $(d, p)$. The results relating to the functions of Fukui and to the local indices of softness are reported in Table 4.

Analysis of the results presented in this table shows that for all of the compounds studied $(\mathbf{7 a - 7 e})$, the nucleophilic attack will preferentially occur on the carbons of the carbonyl groups $(\mathrm{C}=\mathrm{O})$. These are carbons $\mathrm{C} 14$ and $\mathrm{C} 28$ for $7 \mathbf{a}, \mathrm{C} 13$ and $\mathrm{C} 27$ for $7 \mathrm{~b}$ and 7d, C17 and C29 for 7c and finally C21 and C33 for 7e. Concerning the electrophilic attack, it will generally occur on heteroatoms more particularly on sulfur atoms linked to the trigonal carbon $(C=S)$. These are the atoms S18 and S31 for 7a, S17 and S30 for $7 \mathbf{b}$ and 7d, S21 and S33 for 7c and finally S23 and S38 for the compound 7e. For compounds 7c, 7d and 7e, the most reactive sites for electrophilic attacks are also the targets of radical attacks. The radical attack targets for compound $\mathbf{7 b}$ are $\mathrm{C} 28$ and $\mathrm{C} 35$, and those for compound $\mathbf{7 a}$ are $\mathrm{C} 15$ and $\mathrm{C} 27$. 
Table 4. Fukui functions $\left(\mathbf{f}_{\mathbf{k}}^{+} ; \mathbf{f}_{\mathbf{k}}^{-} ; \mathbf{f}_{\mathrm{K}}^{\mathbf{0}}\right)$ and local indices of softness $\left(\mathbf{S}_{\mathbf{K}}^{+} ; \mathbf{S}_{\mathbf{K}}^{-} ; \mathbf{S}_{\mathrm{K}}^{\mathbf{0}}\right)$ of compounds $7 \mathbf{a}-\mathbf{7 e}$.

\begin{tabular}{|c|c|c|c|c|c|c|c|}
\hline Number & Atoms & $f_{k}^{+}$ & $f_{k}^{-}$ & $f_{K}^{0}$ & $S_{K}^{+}$ & $S_{K}^{-}$ & $S_{K}^{0}$ \\
\hline \multicolumn{8}{|c|}{ Compound 7a } \\
\hline 14 & $\mathrm{C}$ & -2.664 & 2.680 & 0.008 & -23.150 & 23.283 & -23.216 \\
\hline 15 & $\mathrm{C}$ & -3.039 & 3.104 & 0.033 & -26.402 & 26.970 & -26.686 \\
\hline 18 & $\mathrm{~S}$ & -8.152 & 7.991 & -0.081 & -70.828 & 69.424 & -70.126 \\
\hline 27 & $\mathrm{C}$ & -3.038 & 3.105 & 0.033 & -26.398 & 26.977 & -26.687 \\
\hline 28 & $\mathrm{C}$ & -2.651 & 2.666 & 0.007 & -23.037 & 23.162 & -23.100 \\
\hline 31 & $\mathrm{~S}$ & -8.158 & 7.988 & -0.085 & -70.877 & 69.404 & -70.141 \\
\hline \multicolumn{8}{|c|}{ Compound $7 \mathrm{~b}$} \\
\hline 13 & $\mathrm{C}$ & -2.669 & 2.742 & 0.073 & -35.539 & 36.508 & -36.024 \\
\hline 17 & $\mathrm{~S}$ & -7.998 & 7.975 & -0.024 & -106.503 & 106.190 & -106.346 \\
\hline 27 & $\mathrm{C}$ & -2.677 & 2.662 & -0.016 & -35.649 & 35.442 & -35.546 \\
\hline 28 & $\mathrm{C}$ & -3.046 & 3.492 & 0.446 & -40.559 & 46.493 & -43.526 \\
\hline 30 & $\mathrm{~S}$ & -7.995 & 8.238 & 0.243 & -106.465 & 109.700 & -108.083 \\
\hline 35 & $\mathrm{C}$ & -3.013 & 3.354 & 0.340 & -40.125 & 44.656 & -42.391 \\
\hline \multicolumn{8}{|c|}{ Compound 7c } \\
\hline 17 & $\mathrm{C}$ & -2.609 & 2.654 & 0.023 & -121.360 & 123.474 & 1.057 \\
\hline 21 & $\mathrm{~S}$ & -7.933 & 8.111 & 0.089 & -369.064 & 377.312 & 4.124 \\
\hline 29 & $\mathrm{C}$ & -2.609 & 2.654 & 0.023 & -121.363 & 123.474 & 1.056 \\
\hline 33 & $\mathrm{~S}$ & -7.933 & 8.111 & 0.089 & -369.067 & 377.316 & 4.124 \\
\hline \multicolumn{8}{|c|}{ Compound 7d } \\
\hline 13 & $\mathrm{C}$ & -2.680 & 2.665 & -0.008 & -19.621 & 19.507 & -0.057 \\
\hline 17 & $\mathrm{~S}$ & -7.988 & 8.146 & 0.079 & -58.483 & 59.639 & 0.578 \\
\hline 27 & $\mathrm{C}$ & -2.666 & 2.652 & -0.007 & -19.520 & 19.412 & -0.054 \\
\hline 30 & $\mathrm{~S}$ & -7.986 & 8.151 & 0.082 & -58.469 & 59.674 & 0.603 \\
\hline \multicolumn{8}{|c|}{ Compound 7e } \\
\hline 21 & $\mathrm{C}$ & -2.680 & 2.660 & -0.010 & -25.090 & 24.902 & -24.996 \\
\hline 23 & $\mathrm{~S}$ & -7.997 & 8.120 & 0.061 & -74.882 & 76.033 & -75.458 \\
\hline 33 & $\mathrm{C}$ & -2.680 & 2.660 & -0.010 & -25.090 & 24.902 & -24.996 \\
\hline 38 & $\mathrm{~S}$ & -7.997 & 8.120 & 0.061 & -74.882 & 76.033 & -75.458 \\
\hline
\end{tabular}

\subsection{NBO Analysis}

The second-order interaction energies between the donor and acceptor orbits (Table 5) measure electronic offshoring in the studied compounds. The higher the value of the interaction energy, the more intense the interaction between the donor and the acceptor. In other words, the greater the tendency for electron donation from donors to electron acceptors, the greater is the scope of the conjugation of the whole system. Also, a greater value of the interaction energy
$\mathrm{E}_{2}$ leads to greater stabilization of the molecular structure by this interaction.

The analysis of the second-order disturbance energies of the Fock matrix by NBO method is listed in Table 5. This table presents the strongest intramolecular interactions, which stabilize each molecule studied. Analysis of the second-order perturbation theory of the Fock matrix shows strong intermolecular hyper conjugative interactions formed by an orbital overlap. 
Table 5. Absorption data obtained by the TD-DFT method at level B3LYP / 6-31G (d, p).

\begin{tabular}{|c|c|c|c|c|c|}
\hline Compounds & Donor (i) & Acceptor (j) & $\mathbf{E}(\mathbf{j})-\mathbf{E}(\mathbf{i})(\mathbf{a}, \mathbf{u})$ & E (2) (kcal/mol) & $\mathbf{F}(\mathbf{i}, \mathbf{j})(\mathbf{a}, \mathbf{u})$ \\
\hline $7 \mathbf{a}$ & $\begin{array}{l}\text { LP (1) N26 } \\
\text { LP (1) N30 } \\
\text { LP (1) N30 } \\
\text { LP (2) S32 } \\
\text { LP (2) O33 }\end{array}$ & $\begin{array}{c}\pi^{*}(\mathrm{C} 11-\mathrm{S} 58) \\
\pi^{*}(\mathrm{C} 27-\mathrm{S} 31) \\
\pi^{*}(\mathrm{C} 28-\mathrm{O} 33) \\
\pi^{*}(\mathrm{C} 27-\mathrm{S} 31) \\
\sigma^{*}(\mathrm{C} 28-\mathrm{N} 30)\end{array}$ & $\begin{array}{l}0.20 \\
0.20 \\
0.32 \\
0.18 \\
0.66\end{array}$ & $\begin{array}{l}\mathbf{7 1 . 5 6} \\
\mathbf{7 1 . 0 3} \\
42.12 \\
34.06 \\
29.45\end{array}$ & $\begin{array}{l}0.106 \\
0.106 \\
0.108 \\
0.072 \\
0.126\end{array}$ \\
\hline $7 b$ & $\begin{array}{l}\sigma(\mathrm{C} 51-\mathrm{O} 45) \\
\sigma(\mathrm{C} 51-\mathrm{H} 54) \\
\sigma(\mathrm{C} 51-\mathrm{H} 54) \\
\sigma(\mathrm{C} 42-\mathrm{O} 45)\end{array}$ & $\begin{array}{l}\sigma^{*}(\mathrm{C} 47-\mathrm{H} 50) \\
\sigma^{*}(\mathrm{C} 28-\mathrm{S} 31) \\
\sigma^{*}(\mathrm{C} 35-\mathrm{C} 36) \\
\sigma^{*}(\mathrm{C} 27-\mathrm{C} 28)\end{array}$ & $\begin{array}{l}0.23 \\
0.03 \\
0.15 \\
0.05\end{array}$ & $\begin{array}{c}\mathbf{2 1 4 5 . 5 2} \\
1458.40 \\
613.29 \\
716.98\end{array}$ & $\begin{array}{l}0.629 \\
0.188 \\
0.274 \\
0.174\end{array}$ \\
\hline $7 c$ & $\begin{array}{c}\sigma(\mathrm{C} 44-\mathrm{O} 52) \\
\sigma(\mathrm{C} 48-\mathrm{O} 52) \\
\mathrm{LP}(1) \text { O52 } \\
\text { LP (1) O52 }\end{array}$ & $\begin{array}{c}\sigma^{*}(\mathrm{C} 2-\mathrm{C} 25) \\
\sigma^{*}(\mathrm{C} 22-\mathrm{C} 25) \\
\sigma^{*}(\mathrm{C} 22-\mathrm{C} 25) \\
\sigma^{*}(\mathrm{C} 42-\mathrm{C} 46)\end{array}$ & $\begin{array}{l}0.96 \\
0.86 \\
0.70 \\
1.05\end{array}$ & $\begin{array}{l}\mathbf{4 1 9 . 1 3} \\
363.62 \\
370.28 \\
153.35\end{array}$ & $\begin{array}{l}0.568 \\
0.501 \\
0.457 \\
0.361\end{array}$ \\
\hline $7 d$ & $\begin{array}{c}\text { LP (1) N25 } \\
\text { LP (2) S16 } \\
\pi(\text { C38-C42) } \\
\pi(\text { C5-C6) } \\
\pi(\text { C1-C2) }\end{array}$ & $\begin{array}{c}\pi^{*}(\mathrm{C} 14-\mathrm{S} 17) \\
\pi^{*}(\mathrm{C} 14-\mathrm{S} 17) \\
\pi^{*}(\mathrm{C} 35-\mathrm{C} 36) \\
\pi^{*}(\mathrm{C} 1-\mathrm{C} 2) \\
\pi^{*}(\mathrm{C} 11-\mathrm{C} 15)\end{array}$ & $\begin{array}{l}0.20 \\
0.18 \\
0.29 \\
0.29 \\
0.27\end{array}$ & $\begin{array}{l}\mathbf{7 1 . 4 0} \\
33.96 \\
22.38 \\
22.23 \\
21.72\end{array}$ & $\begin{array}{l}0.106 \\
0.072 \\
0.072 \\
0.072 \\
0.072\end{array}$ \\
\hline $7 e$ & $\begin{array}{l}\sigma(\mathrm{C} 56-\mathrm{H} 57) \\
\sigma(\mathrm{C} 56-\mathrm{H} 58) \\
\sigma(\mathrm{C} 53-\mathrm{C} 56)\end{array}$ & $\begin{array}{l}\sigma^{*}(\mathrm{C} 36-\mathrm{C} 38) \\
\sigma^{*}(\mathrm{C} 42-\mathrm{C} 44) \\
\sigma^{*}(\mathrm{C} 36-\mathrm{S} 38)\end{array}$ & $\begin{array}{l}0.14 \\
0.06 \\
0.26\end{array}$ & $\begin{array}{c}845.91 \\
\mathbf{6 1 5 0 . 6 6} \\
646.42\end{array}$ & $\begin{array}{l}0.309 \\
0.521 \\
0.361\end{array}$ \\
\hline
\end{tabular}

$E(2)$ signifies the energy of hyper-conjugative interactions (stabilization energy in $\mathrm{kJ} / \mathrm{mol}$ )

Energy difference (au) between the donor and acceptor $N B O$ orbitals $i$ and $j$

$F(i, j)$ is the Fock matrix between the orbitals $i$ and $j(a . u)$

$\boldsymbol{\pi}$ : double bond binding; $\boldsymbol{\pi}^{*}$ : double bond anti-binder; LP: free electron pair; $\boldsymbol{\sigma}:$ single bond; $\boldsymbol{\sigma}^{*}:$ single anti-binding bond.

These overlaps between LP $(\mathrm{N})$ and $\pi *(\mathrm{C}=\mathrm{S})$, LP $(\mathrm{S})$ and $\pi *(\mathrm{C}=\mathrm{O})$ or $\pi *(\mathrm{C}=\mathrm{S}), \mathrm{LP}(\mathrm{O})$ and $\sigma *$ $(\mathrm{CN}), \sigma(\mathrm{CO})$ and $\sigma *(\mathrm{CC})$ or $\sigma *(\mathrm{CH}), \sigma(\mathrm{CH})$ and $\sigma *(\mathrm{CS})$ or $\sigma *(\mathrm{CC}), \sigma(\mathrm{CC})$ and $\sigma *(\mathrm{CS})$, and between $\pi(\mathrm{C}=\mathrm{C})$ and $\pi *(\mathrm{C}=\mathrm{C})$ lead to an Intramolecular Charge Transfer (ICT). These Intramolecular Charge Transfers, in turn, lead to the stabilization of different molecular systems. Thus for compound $7 \mathrm{a}$, the interactions between the nitrogenfree doublets LP (N26) and the double anti-binding bond $\pi *(\mathrm{C} 11-\mathrm{S} 58)$ on the one hand and between the orbitals LP (N30) and the double anti bond $\pi *(\mathrm{C} 27$ $\mathrm{S} 31$ ) on the other hand have respectively stabilization energies of $71.56 \mathrm{kcal} / \mathrm{mol}$ and $71.03 \mathrm{kcal} / \mathrm{mol}$. Concerning molecule $7 \mathrm{~b}$, there is a strong intramolecular interaction between the $\sigma$ (C51-O45) and $\sigma *(\mathrm{C} 47-\mathrm{S} 31)$ orbitals with a stabilization energy value of $2145.52 \mathrm{Kcal} / \mathrm{mol}$. The molecule $7 \mathrm{c}$ is stabilized by the electronic delocalization of the $\sigma$ orbitals towards $\sigma^{*}$, in particular the delocalization of the electrons from $\sigma(\mathrm{C} 44-\mathrm{O} 52)$ to $\sigma *(\mathrm{C} 2-\mathrm{C} 5)$ with stabilization energy of $419.13 \mathrm{kcal} / \mathrm{mol}$. The conjugative interactions of LP (N25) to $\pi *(\mathrm{C} 14-\mathrm{S} 17)$ for compound $\mathbf{7 d}$ and of $\sigma(\mathrm{C} 56-\mathrm{H} 58)$ to $\sigma *(\mathrm{C} 42-$ $\mathrm{C} 44$ ) for compound $7 \mathbf{e}$ lead to stabilization of the molecular systems concerned with energies respective stabilization of $71.40 \mathrm{Kcal} / \mathrm{mol}$ and $6150.66 \mathrm{Kcal} / \mathrm{mol}$.

\subsection{TD-DFT of the Absorption Spectrum of Rhodanine Derivatives}

Using the TD-DFT method, we determined the theoretical absorption spectral of rhodanine nucleus and the molecules $\mathbf{7 a - 7 e}$ vacuum from the ground state of each molecule. These theoretical absorptions spectral are calculated in the gas phase at B3LYP / 6$31+\mathrm{G}(\mathrm{d}, \mathrm{p})$ level. Table 5 compares the excitation energies ( $\Delta$ Eexcit), the wavelengths $(\lambda)$ and the oscillator force ( $f$ ) corresponding to the maximum absorption for rhodanine and its derivatives studied. Figure 3 shows that the dimerization and the addition of substituents, therefore, has a hyperchromic effect on the absorption bands of the rhodanine derivatives. This results in an increase in the absorption intensity of these rhodanine derivatives compared to that of the rhodanine nucleus. There is also an appearance of the absorption bands towards the visible. This increase in wavelengths reflects a bathochromic effect due to the dimerization and the substituents provided. 


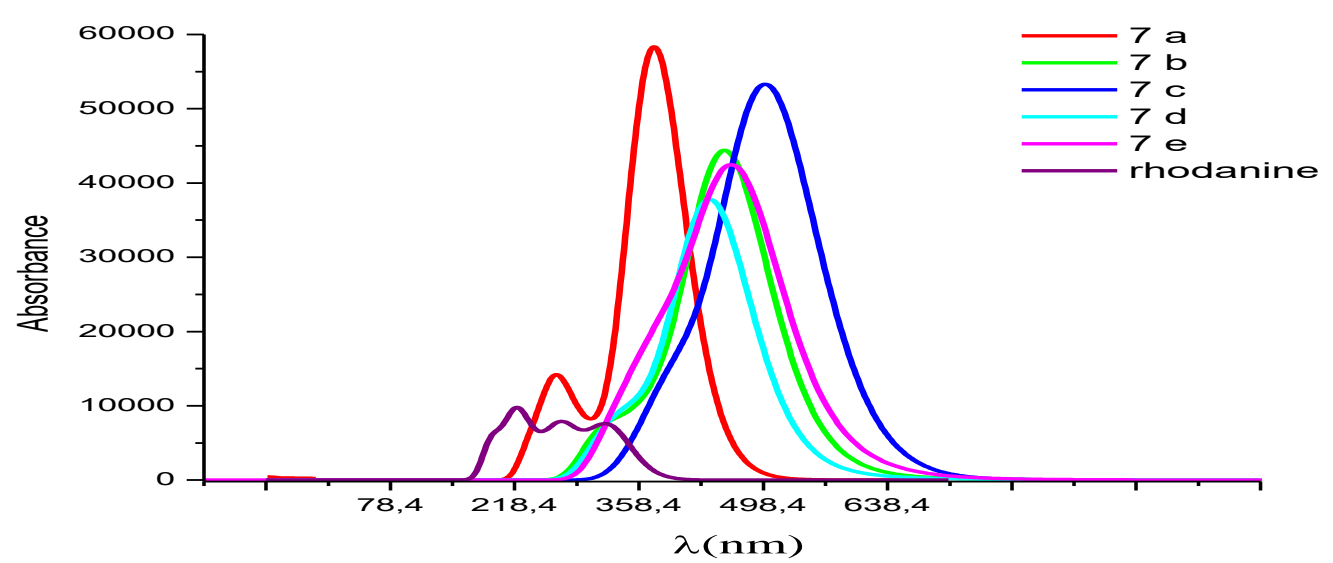

Figure 3. Comparison of the theoretical absorption spectra of rhodanine and its studied derivatives determined by TD-DFT in vacuum

Table 6. Excitation energies $\Delta$ Eexct $(\mathrm{eV})$, wavelengths $\lambda$ (in $\mathrm{nm}$ ), oscillator strength $\mathrm{f}$ and electronic transitions of the absorption maxima of each compound calculated at level B3LYP / 6-31 (d, p) in the void.

\begin{tabular}{|c|c|c|c|c|c|}
\hline Compounds & $\boldsymbol{\Delta E e x c i t}(\mathbf{e V})$ & $\boldsymbol{\lambda}(\mathbf{n m})$ & $\mathbf{f}$ & Electronic transition & Contribution \\
\hline \multirow{2}{*}{ Rhodanine } & 6,169 & 200,987 & 0.198 & HOMO $\rightarrow$ LUMO +4 & $64 \%$ \\
\cline { 2 - 6 } & 5,222 & 237,442 & 0,133 & HOMO-2 $\rightarrow$ LUMO & $59 \%$ \\
\hline \multirow{2}{*}{$\mathbf{7 a}$} & 4,500 & 275,534 & 0,176 & HOMO-1 $\rightarrow$ LUMO & $66 \%$ \\
\hline $\mathbf{7 b}$ & 3,301 & 375,587 & 1,396 & HOMO-1 $\rightarrow$ LUMO +1 & $49 \%$ \\
\hline $\mathbf{7 c}$ & 4,719 & 272,070 & 0,154 & HOMO-1 $\rightarrow$ LUMO & $50 \%$ \\
\hline $\mathbf{7 d}$ & 3,332 & 372,07 & 0,452 & HOMO -2 $\rightarrow$ LUMO & $47 \%$ \\
\hline $\mathbf{7 e}$ & 3,052 & 406,241 & 0,953 & HOMO-1 $\rightarrow$ LUMO+1 & $54 \%$ \\
\hline
\end{tabular}

The rhodanine derivatives studied absorb in the ultraviolet and visible fields. With the exception of 7c, which absorbs in the visible, the absorption spectrum of others has ionizing radiation between 10 and 400 $\mathrm{nm}$. The analysis in Table 6 indicates that the absorption spectrum of all these compounds is observed between 200.987 and $406.241 \mathrm{~nm}$. The rhodanine nucleus has three absorption bands in its UV spectrum. The first at $\lambda=200.987 \mathrm{~nm}$ with excitation energy of $6.169 \mathrm{eV}$ and an oscillator force of 0.198 corresponds to an electronic transition HOMO $\rightarrow$ LUMO +4 (64\%). The second located at $\lambda=237.442 \mathrm{~nm}$ having an oscillator force $\mathrm{f}=0.133$ and energy of $5.222 \mathrm{eV}$ corresponds to an electron displacement according to the transition HOMO-2 $\rightarrow$ LUMO (59\%). The third present at $\lambda=275.534 \mathrm{~nm}$ with an energy of $4.5 \mathrm{eV}$ and an oscillator force $\mathrm{f}=0.176$ results from an electronic displacement HOMO-1 $\rightarrow$ LUMO (66\%). For compound (7a), two bands are observed on its absorption spectrum at $272.73 \mathrm{~nm}$ and $375.587 \mathrm{~nm}$. The absorption band at $272.73 \mathrm{~nm}$ having an oscillator force of 0.154 and excitation energy of $4.719 \mathrm{eV}$ corresponds to an electronic transition
HOMO-1 $\rightarrow$ LUMO (50\%). The band at $375.587 \mathrm{~nm}$ at an excitation energy of $3.301 \mathrm{eV}$ and an oscillation force of 1.396 corresponds to an electronic transition HOMO-1 $\rightarrow$ LUMO + 1 (49\%). For compound (7b) the maximum wavelength is identified at $372.07 \mathrm{~nm}$. This absorption band corresponds to an electronic displacement HOMO-2 $\rightarrow$ LUMO (47\%) with an oscillator force of 0.452 and excitation energy of $3.332 \mathrm{eV}$. For the compound (7c), the absorption band is observed at $406.241 \mathrm{~nm}$ with excitation energy of $3.052 \mathrm{eV}$ and an oscillating oscillation force of 0.953 corresponds to an electronic transfer HOMO-1 $\rightarrow$ LUMO +1 (54\%). The absorption spectral of $7 \mathrm{~d}$ and $7 \mathrm{e}$ show absorption bands at 363.635 and $382.941 \mathrm{~nm}$, respectively. Their respective absorption forces are 0.438 and 0.715 . With excitation energy of $3.41 \mathrm{eV}$ the charge transfer within 7d results from the transition $\mathrm{HOMO} \rightarrow \mathrm{LUMO}+3$ (55\%). The displacement of the electron within 7 th is done according to the transition HOMO-2 $\rightarrow$ LUMO (65\%). All these transitions correspond to an intramolecular charge transfer (TCI). 


\subsection{Influence of the Medium on the Reactivity of Compound 7c}

In this part, we have studied the influence of the medium on the overall reactivity of the most reactive compound 7c. To do this, we have optimized it in different types of solvents (polar and apolar) in order to gauge the stability of these rhodanine derivatives in solvents. It should be noted that these compounds were initially synthesized in Dimethylsulfoxide (DMSO) by Coulibaly et al. ${ }^{7}$. All calculations were made using the DFT method at level 6-31 G (d, p). The results of these calculations are shown in Table 7.

Table 7. Values of the energy gap $\Delta \mathrm{E}(\mathrm{eV})$ and the dipole moment $\mu$ (debye) of compound 7c in different solvents.

\begin{tabular}{|c|c|c|c|c|}
\hline Solvents & $\mathrm{E}_{\text {Hомо }}(\mathrm{eV})$ & $\mathrm{E}_{\text {LUMO }}(\mathrm{eV})$ & $\Delta \mathrm{E}(\mathrm{eV})$ & $\mu(\mathrm{debye})$ \\
\hline DMSO & -0.644 & -2.933 & $\mathbf{3 . 5 0 2}$ & 3.923 \\
\hline Acetone & -6.437 & -2.931 & 3.505 & 3.865 \\
\hline Water & -6.436 & -2.934 & $\mathbf{3 . 5 0 2}$ & 3.942 \\
\hline Methanol & -6.436 & -2.932 & 3.504 & 3.903 \\
\hline Cyclohexane & -6.449 & -2.907 & 3.541 & 3.254 \\
\hline Chloroform & -6.441 & -2.918 & 3.522 & 3.585 \\
\hline
\end{tabular}

According to this table, the value of the energy gap $(\Delta \mathrm{E})$ of $7 \mathrm{c}$ in water is the same in DMSO $(\Delta \mathrm{E}=3.502$ $\mathrm{eV})$. This value is the smallest of all those obtained with other solvents. This compound is, therefore, more reactive in water and in DMSO than in other solvents. The decreasing order of the energy gap is established as follows:

\section{$\Delta \mathrm{E}($ cyclohexane $)>\Delta \mathrm{E}($ chloroform $)>\Delta \mathrm{E}($ acetone $)>\Delta \mathrm{E}($ methanol $)>\Delta \mathrm{E}(\mathrm{DMSO})=\Delta \mathrm{E}($ Water $)$}

This order shows that this compound is more reactive in polar solvents (acetone, methanol, DMSO, and water) than in non-polar solvents (cyclohexane and chloroform). This sequence is similar to that given by the dipole moment $(\mu)$ :

\section{$\mu(($ Water $)>\mu($ DMSO $)>\mu$ (Methanol $)>\mu$ (Acetone $)>\mu$ (Chloroform $)>\mu$ (Cyclohexane $)$}

Indeed, the dipole moment can approximate the partition coefficient $\log \mathrm{P}$, which characterises the solubility of the compounds in aqueous solution. Thus, a strong dipole moment will translate a low solubility in organic solvents and high solubility in water. Compound $\mathbf{7 c}$ is more soluble in aqueous solution and more generally in polar solvents than in non-polar solvents.

\section{Conclusion}

To know the reactive behavior of five newly synthesized rhodanine derivatives (7a element $\mathbf{7 e}$ ), a study was carried out using TD-DFT with the base game 6-31 G (d, p). By calculating HOMO energy, energy gap and global hardness, the conclusion of decreasing order of inhibitory efficiency of the molecules is as follows: $\mathbf{7 c}>\mathbf{7 e}>\mathbf{7 b}>\mathbf{7 d}>\mathbf{7 a}$. The MEP map showed that the negative potential sites are on the sulfur atoms, while the positive potential sites are around the hydrogen atoms. The values of the Fukui functions indicate the sites of nucleophilic and electrophilic attacks. Using Fukui functions, we concluded that for the nucleophilic attack, the reactive sites of the five compounds are the $\mathrm{sp} 2$ hybridized carbons of rhodanine rings carrying the oxygen atoms $(\mathrm{C}=\mathrm{O})$. For electrophilic attacks, the most reactive sites are the sulfur atoms, more particularly those carried by $\mathrm{sp}^{2}$ hybridized carbons $(\mathrm{C}=\mathrm{S})$. The excitation energies, maximum wavelengths, oscillator strength and electronic transitions of each compound were determined using the TD-DFT method at level B3LYP / 6-31 G (d, p). These data allowed us to conclude that the absorption spectrum of all these compounds is observed in the ultraviolet (10-400 nm) except that of 7c, which appears in the visible. The intramolecular electronic transitions which stabilize these compounds are LP $\rightarrow \pi *$ with stabilization energies of 71.56 and $71.4 \mathrm{kcal} . \mathrm{mol}^{-1}$ for $\mathbf{7 a}$ and $\mathbf{7 d}$ respectively and $\sigma \rightarrow \sigma *$ for $7 \mathbf{b}, 7 \mathbf{c}$ and $7 \mathbf{e}$ with respectively $2145.52 ; 419.13$ and $6150.66 \mathrm{kcal}^{\mathrm{mol}}{ }^{-1}$ as stabilization energies. By studying the influence of the medium on compounds $\mathbf{7 a - 7 e}$, it turns out that the rhodanine derivatives are more reactive and more soluble in polar solvents.

\section{References}

1. M. Negwer, Organic-chemical drugs and their synonym:(an international survey), 1994.

2. S. Higashi, H. Akiyama, A. Furuta, M. Takanashi, Y. Li, N. Hattori, Y. Mitsuyama, H. Arai, R. Hanzawa, N. Shibata, Publications from Juntendo University Graduate School of Medicine 2016[2/6], Neurol Sci, 2016, 367, 349-355.

3. E. Zeiger, B. Anderson, S. Haworth, T. Lawlor, K. Mortelmans, W. Speck, Salmonella mutagenicity tests: Results from the testing of 255 chemicals, Environmental Mutagenesis, 1987, 9 (S9 S9), 61-109. 
4. A. Anjaneyulu, V. D. Shukla, G.M. Rao, S. K. Singh, Experimental host range of rice tungro virus and its vectors, Plant Disease, 1982, 66 (1), 54-56.

5. M. Gualtieri, L. Bastide, P. Villain-Guillot, S. Michaux-Charachon, J. Latouche, J.-P. Leonetti, In vitro activity of a new antibacterial rhodanine derivative against Staphylococcus epidermidis biofilms, Journal of Antimicrobial Chemotherapy, 2006, 58 (4), 778-783.

6. Y. Ohishi, T. Mukai, M. Nagahara, M. Yajima, N. Kajikawa, K. Miyahara, T. Takano, Preparations of 5-alkylmethylidene-3carboxymethylrhodanine derivatives and their aldose reductase inhibitory activity, Chemical and pharmaceutical bulletin, 1990, 38 (7), 1911-1919.

7. L. R. Domingo, P. Pérez, Global and local reactivity indices for electrophilic/nucleophilic free radicals, Organic \& biomolecular chemistry, 2013, 11 (26), 4350-4358.

8. S. Pal, R. Roy, A. K. Chandra, Change of hardness and chemical potential in chemical binding, The Journal of Physical Chemistry, 1994, 98 (9), 2314-2317.

9. W. K. Coulibaly, L. Paquin, A. BÚnie, Y.A. BÚkro, R. Le GuÚvel, M. Ravache, A. Corlu, J. P. Bazureau, Prospective study directed to the synthesis of unsymmetrical linked bis-5arylidene rhodanine derivatives via "one-pot two steps" reactions under microwave irradiation with their antitumor activity, Medicinal Chemistry Research, 2015, 24 (4), 1653-1661.

10. C. Lee, W. Yang, R. G. Parr, Development of the Colle-Salvetti correlation-energy formula into a functional of the electron density, Physical review $\mathrm{B}, \mathbf{1 9 8 8}, 37$ (2), 785.

11. K. V. Bohoussou, A. Benié, M. G.-R. Koné, A. B. Kakou, K. Bamba, N. Ziao, Theoretical Study of the Reaction of (2, 2)-Dichloro (Ethyl) Arylphosphine with Bis (2, 2)-Dichloro (Ethyl) Arylphosphine by Hydrophosphination Regioselective by the DFT Method, Computational Chemistry, 2017, 5 (03), 113-128.

12. A. L. Bédé, A. B. Assoma, K. D. Yapo, M. G.R. Koné, S. Koné, M. Koné, B. R. N'Guessan, E.H. S. Bamba, Theoretical Study by Density Functional Theory Method (DFT) of Stability, Tautomerism, Reactivity and Prediction of Acidity of Quinolein-4-One Derivatives, Computational Chemistry, 2018, 6 (03), 57-70.

13. A. Ignaczak, J. N. F. Gomes, Interaction of halide ions with copper, Chemical physics letters, 1996, 257 (5-6), 609-615.

14. M. Lashkari, M. R. Arshadi, DFT studies of pyridine corrosion inhibitors in an electrical double layer, Chemical physics, 2004, 299 (1), 131-137.

15. M. Frisch, G. W. Trucks, H. B. Schlegel, G.E. Scuseria, M. A. Robb, J. R. Cheeseman, G. Scalmani, V. Barone, B. Mennucci,
G. Petersson, Gaussian 09, revision a. 02, gaussian, Inc., Wallingford, CT, 2009, 200.

16. M. J. Frisch, G. W. Trucks, H. B. Schlegel, G.E. Scuseria, M. A. Robb, Cheeseman, JR, J.

A. Montgomery Jr, T. Vreven, K.N. Kudin, J.C. Burant, Revision B. Gaussian, Inc., Pittsburgh PA, 2003.

17. W. Malcolm, J. Chase, JANAF thermochemical table, J. Phys. Chem. Ref. Data, 1985, 14, Supplement No. 1.

18. T. Koopmans, Über die Zuordnung von Wellenfunktionen und Eigenwerten zu den einzelnen Elektronen eines Atoms, Physica, 1934, 1 (1-6), 104-113.

19. D. A. Lerner, C. Balaceanu-Stolnici, J. Weinberg, L. Patron, Computational Study of the Molecular Complexes between 5-HTP with ATP and DHEA. Potential New Drug Resulting from This Complexation, Computational Chemistry, 2015, 3, 18-22.

20. K. Fukui, T. Yonezawa, H. Shingu, A molecular orbital theory of reactivity in aromatic hydrocarbons, The Journal of Chemical Physics, 1952, 20 (4), 722-725.

21. N. Khalil, Quantum chemical approach of corrosion inhibition, Electrochimica Acta, 2003, 48 (18), 2635-2640.

22. C. Lee, W. Yang, R. G. Parr, Development of the Colle-Salvetti correlation-energy formula into a functional of the electron density, Physical review $\mathrm{B}, \mathbf{1 9 8 8}, 37$ (2), 785.

23. P. K. Chattaraj, U. Sarkar, D. R. Roy, Electrophilicity index, Chemical reviews, 2006, 106 (6), 2065-2091.

24. A. U. Orozco-Valencia, J. L. Gázquez, A. Vela, Global and local partitioning of the charge transferred in the Parr-Pearson model, The Journal of Physical Chemistry A, 2017, 121 (20), 4019-4029.

25. R. K. Roy, S. Pal, K. Hirao, On non-negativity of Fukui function indices, The Journal of Chemical Physics, 1999, 110 (17), 8236-8245.

26. J. P. Foster, J. P Foster, F. Weinhold, Natural hybrid orbitals, J. Am. Chem. Soc, 1980, 102, 7211-7218.

27. F. Weinhold, C. R. Landis, Natural bond orbitals and extensions of localized bonding concepts, Chemistry Education Research and Practice, 2001, 2 (2), 91-104.

28. S. K. Pathak, R. Srivastava, A. K. Sachan, O. Prasad, L. Sinha, Am Asiri, M. Karabacak, Experimental (FT-IR, FT-Raman, UV and NMR) and quantum chemical studies on molecular structure, spectroscopic analysis, NLO, NBO and reactivity descriptors of 3, 5-Difluoroaniline, Spectrochimica Acta Part A: Molecular and Biomolecular Spectroscopy, 2015, 135, 283-295.

29. K. A. R. Kouassi, A. Benié, M. G.-R. Koné, W. K. Coulibaly, K. V. Bohoussou, A. Ganiyou, Predictive Modeling of the Human Hepatoma (Huh-7D12) Cancer Line of a Series of bis-(5- 
arylidene-rhodanine-3-yl) Diamine, Asian Journal of Chemical Sciences, 2019, 1-11.

30. W. K. Coulibaly, J. S. N'dri, M. G.-R. Koné, C. D. Dago, C. N.'t. Ambeu, J.-P. Bazureau, N. Ziao, Studies of the Chemical Reactivity of a Series of Rhodanine Derivatives by Approaches to Quantum Chemistry, Computational Molecular Bioscience, 2019, 9 (03), 49.

31. D. Soro, L. Ekou, M. G.R. Koné, T. Ekou, N. Ziao, DFT Study of Molecular Stability and Reactivity on Some Hydroxamic Acids, European Journal of Engineering Research and Science, 2019, 4 (2), 45-49.

32. Z. Demircioğlu, Ç. Albayrak, O. Büyükgüngör, Theoretical and experimental investigation of (E)-2-([3, 4-dimethylphenyl) imino] methyl)-3methoxyphenol, Journal of Molecular Structure, 2014, 1065, 210-222.
33. H. Gökce, S. Bahçeli, Analysis of molecular structure, spectroscopic properties (FT-IR, microcalculations of free and ligand 2-thiopheneglyoxylic acid in metal halides $(\mathrm{Cd}, \mathrm{Co}, \mathrm{Cu}, \mathrm{Ni}$ and Zn), Spectrochimica Acta Part A: Molecular and Biomolecular Spectroscopy, 2013, 116, 242250.

34. F. J. Luque, J. M. López, M. Orozco, Perspective on "Electrostatic interactions of a solute with a continuum. A direct utilization of ab initio molecular potentials for the prevision of solvent effects", Theoretical Chemistry Accounts, 2000, 103 (3-4), 343-345.

35. S. Sebastian, N. Sundaraganesan, The spectroscopic (FT-IR, FT-IR gas phase, FT-Raman and UV) and NBO analysis of 4-Hydroxypiperidine by density functional method, Spectrochimica Acta Part A: Molecular and Biomolecular Spectroscopy, 2010, 75 (3), 941-952. 